solid scientific and philosophical footing for its support.

CHERYL FOSTER Assistant Professor, University of Rhode Island, USA.

\section{The Nuffield video library in medical ethics and law}

Produced and directed by Len Doyal. Available to health care institutions (limited number available) from Len Doyal, The London Hospital Medical College, Turner Street, London $\mathrm{E} 12 \mathrm{AD}, £ 100.00$

Anyone who has tried to make videotape recordings for use in teaching medical ethics will appreciate Len Doyal's achievement. The Nuffield Video Library in Medical Ethics and Law consists of six tapes, each containing about 45 minutes of wellstructured and relevant material. A handbook of useful reprinted articles is also included.

The tapes are dedicated to the memory of John Dawson who died at a tragically young age. John Dawson made a tremendous contribution to practical medical ethics in Britain. His clear-headed enthusiasm was a support and stimulus to many of us working in this field. I found it both a sadness and a pleasure to see him on the third of these tapes performing with his characteristic energy.

Each tape is a five-course meal. The starter is an introduction to the topic given by Len Doyal himself. The entrée is a case presentation in which a senior clinician describes a particular patient whose care raised ethical problems relevant to the theme of the tape. The main course, the clinical perspective, is an interview between Len Doyal and an experienced doctor in which some of the theoretical issues raised in the introduction are looked at in more detail. The pudding is a role-play of an interview between doctor and patient, and the meal ends with a brief summary and conclusion.

The tapes as a whole represent the menus for a week; assuming the restaurant staff have an evening off. The topics of the six tapes are as follows: informed consent and good medicine; telling the truth and good medicine; confidentiality and good hospital medicine; informed consent and good psychiatry; and informed consent and good general practice. The assumption is that good medical practice requires a sensitivity to, and an ability to think about, the ethical aspects of medicine; this is an assumption with which few of the readers of this journal will disagree. On the whole Dr Doyal is more concerned to raise ethical issues and to identify the main principles involved than to promote a particular ethical viewpoint. No sustained discussion of medical ethics, however, can be ethically neutral and these tapes present the prevailing perspective in medical ethics (if not the prevailing practice): that it is patients' autonomy which is of prime importance. The choice of topics shows a central concern with what might be broadly considered the doctor-patient relationship: the focus is on consent, confidentiality and truth-telling.

The first thing to be said about these tapes is that they are interesting. The interviews with, for example, Anthony Clare or John Dawson are simply fun to watch; and some of the role-play scenes are gripping. Their value however, stands or falls with their merit as aids to teaching. Each tape is designed to form a unit which can, in theory, be watched from start to finish with suitable pauses for discussion. I doubt, however, whether many teachers of medical ethics will want to use the tapes in this way. I find that video material is most effective in seminar teaching when it is fairly short and when it is only a part of the teaching session. I serve the courses, rather than the meals, to my students. In a seminar on consent, for example, which I run with first-year clinical medical students while they are working on the surgical wards, I have used two sections of the first tape. On some occasions I have chosen the role-play which involves a surgeon trying to persuade a woman to have a mastectomy rather than a 'lumpectomy'. This acts as a stimulating starting point to the seminar and leads students directly into thinking about models of the doctorpatient relationship and what the different models mean in practice. The other part of this tape which I have used is the interview with the surgeon, $\mathrm{Mr}$ John Cochrane. Essentially $\mathrm{Mr}$ Cochrane argues for the importance of obtaining informed consent prior to surgery from both ethical and legal standpoints. In addition he proposes a simple structure for thinking about the risks of surgery: the risks of any operation involving a general anaesthetic; the special risks of this particular operation, and the alternative treatments. Simple though this is it provides medical students with a way of organising their thoughts. The value, I find, in showing the video is that the main message, the importance of taking informed consent seriously, comes from $\mathrm{Mr}$ Cochrane. This is important because a central problem in teaching ethics to medical students is that it is those students who engage least with such teaching who need it most. When I, a psychiatrist with a special interest in ethics, stress to such students the importance of informed consent it is easy for them to ignore my message. But when a senior and successful surgeon, who looks like a senior and successful surgeon, gives the message it has more impact. With thirty 'courses' to choose from, teachers of health care ethics will find that these tapes contain much of value for their seminar teaching.

TONY HOPE

Leader, Oxford Practice Skills Project, Oxford University Medical School, Oxford and Editorial Associate Journal of Medical Ethics.

\section{Philosophical ethics in reproductive medicine}

Edited by David R Bromham,

Maureen E Dalton and Jennifer C Jackson, Manchester, Manchester University Press, 1990, 261 pages, $£ 40.00$

This book comprises the proceedings of the First International Conference on Philosophical Ethics in Reproductive Medicine (PERM) held at the University of Leeds in April 1988. The main lectures of this conference are grouped in six parts, equivalent to the conference sessions: the embryo; society and assisted conception; the neonate; termination of pregnancy; clinical trials in obstetrics, and informed consent. Each part concludes with a representation of the discussion following the delivery of the papers.

Of the twenty-two contributors, just under half are from the medical professions, the remaining half comprising professional philosophers, theologians, lawyers, and academics involved in the general field of medical 
ethics. This range means that the collection can be read in two main ways. First, it can be read simply for factual information. In this respect, perhaps unsurprisingly, it is the contributions that are predominantly medicine-based and law-based that are generally the most useful.

Secondly, the book can be read for clarification of the ethical issues surrounding reproductive technology. Here, the reader is immediately confronted by a catholicity of the concepts of ethics. For example, ethics refers sometimes to what appears on the agenda of a hospital ethics committee (in Richard West's contribution), to a specific moral or religious stance which is commended to practitioners (in the contributions of Richard Lilford and Jack Mahoney), and sometimes to a branch of academic philosophy (in Anne Fagot-Largeault's contribution).

This catholicity does of course represent the wide range of opinion in medical ethics, but in a single collection it inevitably poses a problem. Despite the convenient grouping of the book according to substantive topics, the sheer range of approaches makes it difficult for the reader to identify the precise points at which different contributors would agree or disagree. The discussions go part of the way towards such an identification, but, like most conference discussions, they reveal a fair amount of mutual misunderstanding between contributors. It is probably for these reasons that the most successful part of the book is where withholding neonatal care is examined first by Alexander Campbell as a paediatrician and, in response, by Jennifer Jackson as a philosopher. Here, and in the usefully delimited discussion that follows, genuine debate is discernible, taking the level of analysis beyond that of mere juxtaposition of diverse views.

ELIZABETH KINGDOM Department of Sociology, Social Policy and Social Work Studies, University of

Liverpool.

\section{Protecting the vulnerable: autonomy and consent in health \\ care}

Edited by Margaret Brazier and Mary Lobjoit, 183 pages $+\mathrm{xi}$, London, 1991. Routledge, $£ 30.00$
This volume in the 'Social ethics and policy' series is a collection of papers, some of which were originally given as part of a public lecture series in Manchester in 1988. The unifying theme is the ethical and legal problems of making health-care decisions in cases where patients are, or at least are thought to be, partially or completely incapable of making valid decisions for themselves. This unity at one level of course conceals enormous variety at another, since the forms which such actual or apparent incompetence can take are incredibly varied, as are the decisions which have to be taken in providing care for such patients. The ethical problems generated are equally varied. Thus the papers range over very premature babies, people with mental handicap, women undergoing sterilisation, subjects of non-therapeutic research, people with suicidal tendencies and those receiving psychotherapy, especially students. In addition to the discussions of particular types of decision, there are also more theoretical papers about the nature of autonomy, informed consent and the right to information.

The papers on particular types of case are on the whole sensible, practical and sensitive, but hardly groundbreaking. The policy recommendations made are usually plainly right but there often seems to be a reluctance really to get to grips with the ethical complexities of a situation. For instance, Heather Draper, writing about the sterilisation of mentally handicapped women, recommends a review of the law concerning wardship and research into the attitudes of mentally disabled women towards pregnancy, labour and children - both eminently sensible suggestions. But the ethical issue in such cases - the balance to be drawn between the interests of the woman herself, those of the people who care for her and those of the potential child - is referred to but never really explored in her paper, and she comes to the conclusion that sterilisations must be 'solely in the interests of the individual concerned'.

An exception to this line of criticism is Gavin Fairbairn's paper 'Suicide and justified paternalism'. Drawing both on his reflections on his own professional experience and on a subtle philosophical analysis, Fairbairn succeeds in moving beyond the tired discussions of the right to suicide and gives an account of the ethics of preventing suicide which makes due allowance for the interests of those other than the suicider who are involved. In the course of this, he also has interesting general things to say about, for instance, paternalism: much, he says, of what passes for paternalism is really 'self-interested pseudo-paternalism because it is more concerned with protecting its perpetrator than with caring for the welfare of the individual in question'.

The more theoretical papers are variable in quality. Margaret Brazier very thoroughly examines the legal problems of treating incompetent patients, but rightly concludes that the rights of, for example, mentally handicapped people depend far more on general social attitudes to disabled people than on legal frameworks. Richard Lindley's paper on a doctor's duty to inform patients of the facts in cases of surgery comes to interesting conclusions, recommending a form of the Bolam test which takes in groups other than medical experts. Harry Lesser provides a useful discussion of the patient's right to information. Alastair Campbell's paper, however, seems simply confused. He makes great play with the notion thate patients are dependent on their doctors, as they clearly are, but seems to think that that implies limits to the value of patient autonomy rather than being precisely the reason why respect for patient autonomy is needed.

ERIC MATTHEWS Department of Philosophy, University of Aberdeen.

\section{Organ replacement therapy: ethics, justice, commerce}

First joint meeting of ESOT

(European Society for Organ

Transplantation) and

EDTA/ERA(European Renal

Association) in Munich, 11-14

December, 1990. Edited by W Land and J B Dossetor, 578 pages + xxiii, London and Berlin, 1991. SpringerVerlag, £78.50

The contents pages of this volume list 81 papers, five transcripts of plenary discussion sessions, and 201 contributors, giving some idea as to the huge input the conference it is based upon received. The articles range in kind from those which are more or less purely medical, though having 